\title{
Texas Section Photo Contest
}

This year's winners of the annual photo contest conducted by the Society for Range Management's Texas Section illustrate the beauty and value of rangelands. The Grand Champion photo, submitted by Forest Smith, appears on the cover of this issue; second and third place entries are below. For more information on the photo contest see the Texas Section's website: http://www.rangelands.org/texasl.

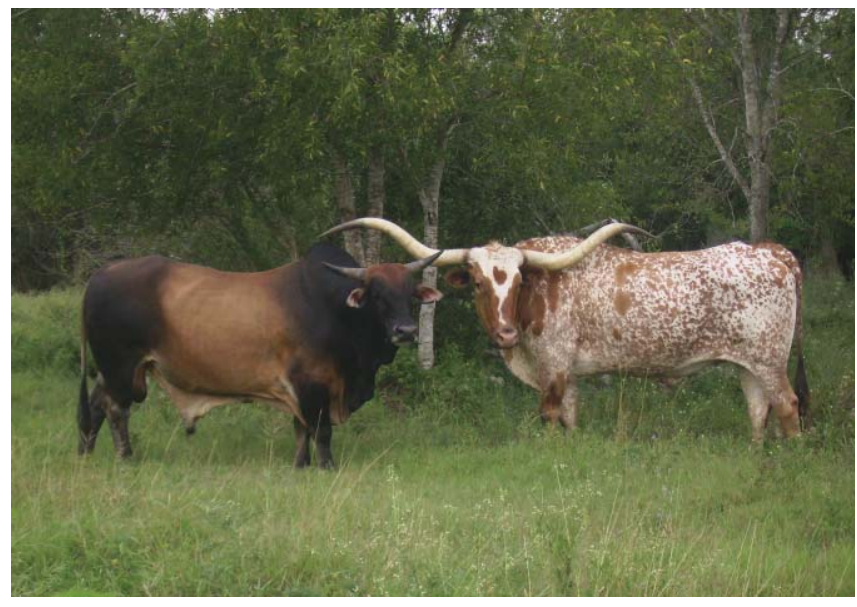

Reserved champion photo: herd bulls on Tres Arroyos Ranch, near Alice, Texas. Photo by Bruce Healy.

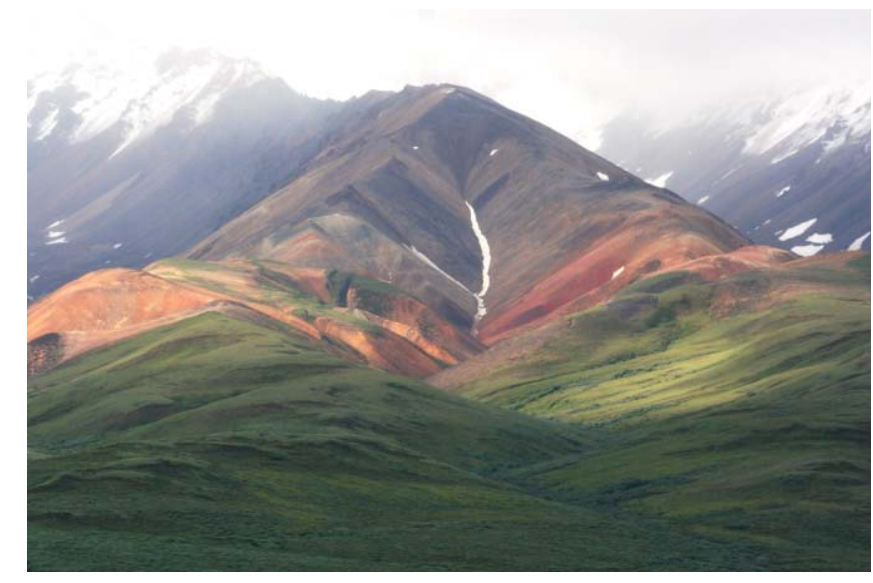

Third place photo: color landscape, Alaska. Photo by Clint Rollins. 